Revue internationale P.M.E.

\title{
La performance des incubateurs
}

proposition et validation d'un modèle de mesure

multidimensionnel

Incubator performance

Presentation and validation of a multidimensional evaluation model

\section{El desempeño de las incubadoras}

\author{
propuesta y validación de un modelo de evaluación \\ multidimensional
}

\section{Chaffik Bakkali, Karim Messeghem et Sylvie Sammut}

Volume 27, numéro 3-4, 2014

URI : https://id.erudit.org/iderudit/1028044ar

DOI : https://doi.org/10.7202/1028044ar

Aller au sommaire du numéro

Éditeur(s)

Editions EMS - In Quarto SARL

ISSN

0776-5436 (imprimé)

1918-9699 (numérique)

Découvrir la revue

Citer cet article

Bakkali, C., Messeghem, K. \& Sammut, S. (2014). La performance des incubateurs : proposition et validation d'un modèle de mesure multidimensionnel. Revue internationale P.M.E., 27(3-4), 145-171. https://doi.org/10.7202/1028044ar

\section{Résumé de l'article}

Dans le champ entrepreneurial, la recherche sur les incubateurs prend un poids sans cesse grandissant. Le rôle que ces structures sont censées jouer dans la réussite des entrepreneurs explique cet intérêt croissant du monde académique. Ce dernier s'intéresse tout particulièrement à la question de la performance des incubateurs. Ce questionnement est d'autant plus prégnant aujourd'hui que le contexte actuel est marqué par une limitation de la ressource publique qui amène à s'interroger avec davantage d'insistance sur l'efficacité de structures financées le plus souvent par des collectivités locales. Néanmoins, la recherche sur la performance des incubateurs n'a pour l'heure pas encore été en mesure de faire émerger un modèle de mesure pleinement satisfaisant. En effet, les premiers travaux ont eu trop tendance à appréhender la performance des incubateurs sous l'angle d'une seule perspective. Des travaux plus récents ont cependant montré que le balanced scorecard peut constituer un moyen de pallier ces limites grâce à une mesure équilibrée de la performance. C'est pourquoi cette contribution se propose d'identifier des dimensions et indicateurs permettant de mesurer la performance des incubateurs par le biais du balanced scorecard. À partir d'une étude quantitative, fondée sur un questionnaire en ligne auquel 109 responsables d'incubateur français ont répondu, ce sont 12 dimensions et 35 indicateurs de performance qui ont été validés. D’un point de vue théorique, cette validation empirique montre l'intérêt d'agréger les multiples dimensions de la performance des incubateurs au sein d'un même modèle de mesure. D'un point de vue managérial, les financeurs et les responsables d'incubateur se voient offrir un nouvel outil de mesure et de pilotage de la performance qui tient compte de toute la complexité de l'incubation. 


\title{
La performance des incubateurs: proposition et validation d'un modèle de mesure multidimensionnel
}

\author{
Chaffik BAKKALI
}

Chaffik Bakkali est maître de conférences à l'Université Montpellier 1. Titulaire d'un doctorat en sciences de gestion (Université Montpellier 1,2013), ses travaux portent sur l'accompagnement entrepreneurial pour lesquels il a obtenu le prix de thèse AEI-FNEGE 2014 qui distingue annuellement la meilleure recherche doctorale française dans le champ entrepreneurial.

\author{
UFR AES - Université Montpellier 1 \\ Avenue Raymond Dugrand - CS 59640 \\ 34960 MONTPELLIER CEDEX 2, France \\ chaffik.bakkali@univ-montp1.fr
}

Karim MESSEGHEM

Karim Messeghem est professeur agrégé des Universités en sciences de gestion à l'Université Montpellier 1 et directeur du Labex Entreprendre. Titulaire d'un doctorat en sciences de gestion (Université Montpellier 1, 1999), ses travaux portent sur l'accompagnement entrepreneurial, l'opportunité entrepreneuriale et les stratégies des PME. Ils sont menés au sein du Laboratoire MRM (Montpellier Recherche en Management) dont il assure la direction de l'équipe Entrepreneuriat.

\author{
UFR AES - Université Montpellier 1 \\ Avenue Raymond Dugrand - CS 59640 \\ 34960 MONTPELLIER CEDEX 2, France \\ karim.messeghem@univ-montp1.fr
}

Sylvie SAMMUT

Sylvie Sammut est maître de conférences HDR à l'Université Montpellier 1. Titulaire d'un doctorat en sciences de gestion (Université Montpellier 1, 1995) et d'une habilitation à diriger des recherches en sciences de gestion (Université Montpellier 1, 2009), ses travaux portent sur l'accompagnement entrepreneurial. Vice-Présidente de l'Académie de l'Entrepreneuriat et de l'Innovation, elle est co-rédactrice en chef de la Revue de l'Entrepreneuriat.

ISEM - Université Montpellier 1

Rue Vendémiaire - CS 19519

34960 MONTPELLIER CEDEX 2, France

sylvie.sammut@univ-montp1.fr 


\begin{abstract}
RÉSUMÉ
Dans le champ entrepreneurial, la recherche sur les incubateurs prend un poids sans cesse grandissant. Le rôle que ces structures sont censées jouer dans la réussite des entrepreneurs explique cet intérêt croissant du monde académique. Ce dernier s'intéresse tout particulièrement à la question de la performance des incubateurs. Ce questionnement est d'autant plus prégnant aujourd'hui que le contexte actuel est marqué par une limitation de la ressource publique qui amène à s'interroger avec davantage d'insistance sur l'efficacité de structures financées le plus souvent par des collectivités locales. Néanmoins, la recherche sur la performance des incubateurs n'a pour l'heure pas encore été en mesure de faire émerger un modèle de mesure pleinement satisfaisant. En effet, les premiers travaux ont eu trop tendance à appréhender la performance des incubateurs sous l'angle d'une seule perspective. Des travaux plus récents ont cependant montré que le balanced scorecard peut constituer un moyen de pallier ces limites grâce à une mesure équilibrée de la performance. C'est pourquoi cette contribution se propose d'identifier des dimensions et indicateurs permettant de mesurer la performance des incubateurs par le biais du balanced scorecard. À partir d'une étude quantitative, fondée sur un questionnaire en ligne auquel 109 responsables d'incubateur français ont répondu, ce sont 12 dimensions et 35 indicateurs de performance qui ont été validés. D'un point de vue théorique, cette validation empirique montre l'intérêt d'agréger les multiples dimensions de la performance des incubateurs au sein d'un même modèle de mesure. D'un point de vue managérial, les financeurs et les responsables d'incubateur se voient offrir un nouvel outil de mesure et de pilotage de la performance qui tient compte de toute la complexité de l'incubation.
\end{abstract}

MOTS CLÉS

Incubateurs, Performance, Modele de mesure, Indicateurs

\title{
Incubator performance : presentation and validation of a multidimensional evaluation model
}

\begin{abstract}
In the field of entrepreneurship studies, research on incubators is in full expansion. Scholars are increasingly interested in these structures because of their key role in entrepreneurial success, and they have particularly focused on the issue of evaluating incubator performance. Reliable tools for evaluation are a pressing need in today's context of limited public resources, and local governments, which provide most of the funding, are thus all the more insistent on efficiency. Nevertheless, the research on this topic to date has not yet yielded an evaluation model that has been fully satisfactory. Our review of the literature indeed indicates that previous works have tended to assess incubator performance from a single perspective only. In contrast, we propose a new multidimensional model based on the balanced scorecard, which has a clear advantage over earlier models: the many facets of incubator performance can be evaluated to give a global picture of efficiency. In addition to presenting the model, however, we also empirically validate its utility through a quantitative study based on the responses of 109 French incubator managers to an online questionnaire. From a theoretical perspective, this empirical validation shows the interest of aggregating several performance indicators into a single evaluation model. From a management perspective, both funding sources and incubator managers have a new tool at their disposal for evaluating and guiding performance while taking into account the great complexity of the incubation process.
\end{abstract}

KEYWORDS

Incubators, Performance, Evaluation model, Indicators 


\title{
El desempeño de las incubadoras : propuesta y validación de un modelo de evaluación multidimensional
}

\begin{abstract}
RESUMEN
En el área de la emprendeduría, el peso específico de la investigación sobre las incubadoras de empresas está en constante aumento. El papel que esas estructuras parecen desempeñar en el éxito de los emprendedores explica el creciente interés del mundo académico. Éste muestra un interés muy especial por la cuestión de la evaluación del desempeño de las incubadoras. Este cuestionamiento es tanto más acuciante hoy en día cuanto que el contexto actual está marcado por una limitación de los recursos públicos, lo cual conlleva interrogarse con mayor insistencia sobre la eficacia de estructuras financiadas muy a menudo por Entidades Locales. No obstante, la investigación en materia de evaluación del desempeño de las incubadoras no ha logrado por ahora la emergencia de un modelo de evaluación plenamente satisfactorio. Por medio de una revista de literatura, esta contribución muestra efectivamente que los trabajos precedentes han tenido una tendencia excesiva a enfocar el desempeño de las incubadoras desde el punto de vista de una única perspectiva Para subsanarlo, se propone un nuevo modelo de evaluación basado en el balanced scorecard. El interés de este modelo se fundamenta en su carácter multidimensional que permite valorar las múltiples facetas del desempeño de las incubadoras. Empero, esta contribución no se limita a proponer un nuevo modelo de evaluación. En efecto, permite asimismo validar empíricamente su pertinencia gracias a un estudio cuantitativo basado en un cuestionario on-line al que han respondido 109 responsables de incubadoras francesas. Desde un punto de vista teórico esta validación empírica muestra el interés que supone agregar las múltiples dimensiones del desempeño de las incubadoras dentro del mismo modelo de evaluación. Desde el punto de vista de la gerencia se ofrece a los financiadores y a los responsables de incubadoras una nueva herramienta de evaluación y de pilotaje del desempeño que tiene en cuenta toda la complejidad de la incubación.
\end{abstract}

Palabras Clave

Incubadoras, Desempeño, Modelo de evaluación, Indicadores

\section{INTRODUCTION}

Les incubateurs sont des structures qui ont été pensées pour apporter un soutien aux entrepreneurs dans le développement de leurs idées d'affaires (Chabaud, Ehlinger et Perret, 2004 ; Ratinho et Henriques, 2010). En Europe, ils sont le plus souvent financés par des fonds publics et constituent ainsi une des composantes clés de la politique publique entrepreneuriale des collectivités locales (Aernoudt, 2004). Comme pour toute politique publique, la question de l'efficacité de l'action menée se pose très rapidement (Arlotto, Sahut et Teulon, 2011). Pour les responsables d'incubateur, la maximisation de cette efficacité passe par une transposition réussie des méthodes du management privé vers le management public. Il leur faut donc trouver le moyen d'impulser un management par les objectifs (efficacité) tout en réduisant les moyens engagés (efficience) et en améliorant la satisfaction des bénéficiaires de l'accompagnement (effectivité). C'est une des raisons pour lesquelles les pouvoirs publics encouragent de plus en plus les responsables d'incubateur à développer des outils de mesure et de pilotage de la performance. À cette raison viennent s'en greffer d'autres tout aussi, pertinentes. 
La mesure de la performance facilite le benchmarking des incubateurs et permet ainsi une amélioration générale des pratiques d'incubation (Tornatzky, Sherman et Adkins, 2002 ; Lewis, 2008). Cette question de l'amélioration des pratiques est d'autant plus cruciale que le coût que représentent les incubateurs n'est pas anodin (McMullan, Chrisman et Vesper, 2001). Pour les entrepreneurs, ce coût se comptabilise essentiellement en termes de temps passé au sein des structures d'incubation. Pour les collectivités locales, il se mesure en termes de fonds publics qu'elles allouent aux incubateurs (Hackett et Dilts, 2004) mais, cette allocation de fonds ne peut être maintenue durablement sans une justification réelle de la performance des structures d'incubation. C'est pourquoi la mesure de la performance est à la fois importante pour les incubateurs et leurs financeurs (collectivités locales). Ces derniers peuvent également se servir de cette mesure de la performance pour mieux répartir les fonds entre les structures d'incubation et permettre une plus grande efficacité de la ressource publique (Commission européenne, 2002). Au-delà des financeurs, les informations sur la performance des incubateurs peuvent aussi être utiles aux deux autres parties prenantes que sont les responsables d'incubateur et les entrepreneurs. Les premiers peuvent s'appuyer sur ces informations pour mieux positionner leur propre incubateur au sein de l'environnement local et développer des stratégies davantage pertinentes (Tornatzky, Sherman et Adkins, 2002). Les seconds peuvent se fonder sur ces informations pour déterminer l'incubateur qu'ils souhaitent rejoindre en fonction de son niveau de performance réel (Bigliardi, Dormio, Nosella et Petroni, 2006).

Dans cette contribution, la notion d'incubateur est appréhendée dans son acceptation anglo-saxonne "incubator", c'est-à-dire comme un terme ombrelle qui regroupe différentes structures qui visent à apporter un soutien aux entrepreneurs (Lewis, 2001 ; Aernoudt, 2004 ; Bøllingtoft, 2012). Dans le contexte français, cela revient à regrouper sous ce même terme deux différents types de structures : les incubateurs stricto-sensu et les pépinières d'entreprises. Les premiers seraient positionnés sur un accompagnement ante-création des entrepreneurs, alors que les seconds seraient sur un accompagnement postcréation. La réalité est néanmoins plus complexe, car certaines structures se positionnent sur l'ensemble de la chaîne de valeur de l'accompagnement à la création d'entreprise. C'est pourquoi l'objet d'étude dans cet article correspond à l'ensemble de ces structures regroupées sous le terme d'incubateur. L'aide proposée par un incubateur peut prendre la forme d'un hébergement, de services administratifs, d'un accès à des ressources financières, de conseils et d'une mise en réseau (Carayannis et Von Zedtwitz, 2005).

Par ailleurs, bien que les motivations à son développement soient nombreuses, la mesure de la performance des incubateurs reste limitée par la difficulté récurrente à définir des indicateurs de performance pertinents (Phan, Siegel et Wright, 2005). Cela tient au fait qu'une grande partie des incubateurs ne poursuit pas une logique de profit (Voisey, Gornall, Jones et Thomas, 2006). Par conséquent, les indicateurs financiers traditionnellement mobilisés pour juger de la performance d'entreprises privées ne peuvent pas être utilisés dans le contexte de l'incubation. Si des tentatives ont été menées pour identifier des indicateurs pertinents pour mesurer la performance des incubateurs, elles restent pour la plupart inabouties. En effet, les précédents modèles de mesure développés dans la littérature ont le plus souvent occulté le caractère multidimensionnel de la performance des structures d'incubation (Vanderstraeten et Matthyssens, 2010). Des travaux récents ont toutefois montré que le balanced scorecard peut permettre de remédier à ces limites et constituer un moyen pertinent 
pour appréhender la performance des incubateurs (Messeghem, Naro et Sammut, 2010 ; Bakkali, Messeghem et Sammut, 2013). Mais si ces travaux ont pour principal intérêt d'avoir tracé une nouvelle voie grâce au balanced scorecard, ils ne mettent pas en évidence les indicateurs qui pourraient constituer celui-ci dans le contexte de l'incubation. Ce constat nous amène à la formulation de la question de recherche suivante : à partir de quels indicateurs et dimensions est-il possible de structurer une mesure de la performance des incubateurs autour du balanced scorecard?

L'objectif de cette contribution est donc d'identifier et de valider des dimensions et indicateurs pertinents pour appréhender la performance des incubateurs par le biais du balanced scorecard. Pour ce faire, un cadre méthodologique reposant sur quatre étapes de recherche successives a été mis en place. Dans cet article, l'intérêt va se porter essentiellement sur la dernière de ces quatre étapes, puisque c'est celle-ci qui permet finalement de juger de la pertinence du modèle de mesure développé autour du balanced scorecard. Cette dernière étape de recherche consiste en une étude quantitative qui a été conduite à partir d'un questionnaire en ligne auquel 109 responsables d'incubateur français ont répondu. Les résultats de cette étude permettent de valider chacune des 12 composantes du modèle de mesure développé, ainsi que 35 indicateurs de performance qui se répartissent dans ces composantes.

La première partie de cette contribution passe en revue les précédents travaux conduits sur la performance des incubateurs et montre l'intérêt d'un modèle de mesure fondé sur le balanced scorecard. La deuxième partie expose la méthodologie qui a été retenue afin de vérifier la pertinence d'un tel modèle. Les troisième et quatrième parties permettent enfin de présenter et de discuter les résultats de cette recherche.

\section{LA LITTÉRATURE SUR LA PERFORMANCE DES INCUBATEURS : UNE LECTURE MULTIDIMENSIONNELLE}

L'incubation constitue un champ de recherche relativement récent, puisque les premiers travaux ne se sont développés que dans les années 1980. En raison de cette relative jeunesse du champ de recherche, la littérature s'y rattachant manque parfois de clarté, de cohésion, voire même de consensus (Hackett et Dilts, 2004). La question de la performance des incubateurs en est la parfaite illustration.

\subsection{Quel impact des incubateurs?}

De multiples études ont été menées ces dernières années sur la performance des incubateurs (Lewis, 2008; Arlotto, Sahut et Teulon, 2011). Malgré cela, il reste encore difficile aujourd'hui d'établir avec clarté si les incubateurs contribuent réellement à améliorer les chances de réussite des entreprises qui recourent à l'incubation, tant les résultats ont tendance à être contradictoires. Par exemple, les travaux de Mian (1997) ou de Colombo et Delmastro (2002) montrent que les entreprises incubées connaissent généralement une croissance de leur chiffre d'affaires et de leur nombre d'employés plus important, ou encore qu'elles ont tendance à être plus actives en termes d'innovation, que des entreprises similaires non incu- 
bées. Un débat s'est cependant engagé sur la validité des résultats de ces études en raison des difficultés méthodologiques rencontrées pour constituer des échantillons de contrôle ayant exactement la même localisation, la même activité et le même âge que les entreprises incubées (Mian, 1997). C'est la raison pour laquelle il existe des études aux résultats contradictoires qui montrent une absence de lien significatif entre les incubateurs et la réussite des incubés (Tamasy, 2007).

À ces problèmes méthodologiques liés à la constitution d'échantillons de contrôle s'ajoute également un biais de sélection des incubés (Kuratko et LaFollette, 1987 ; Merrifield, 1987 ; Smilor, 1987 ; Lumpkin et Ireland, 1988 ; Allen et McCluskey, 1990 ; Bearse, 1998 ; Aerts, Matthyssens et Vandenbempt, 2007 ; Bergek et Norman, 2008). En effet, les incubateurs mettent généralement en place des processus pour ne sélectionner et incuber que des projets présentant un fort potentiel de développement. Hackett et Dilts (2004) défendent l'idée que les incubateurs ne devraient sélectionner que les projets qui sont «faibles, mais prometteurs ». Cependant, avec la pression à la performance que subissent les incubateurs, la tentation est réelle de ne sélectionner que les meilleurs projets afin de présenter des résultats aussi élevés que possible. Ce constat amène Bearse (1998) à s'interroger sur la portée réelle de l'incubation quant au succès des incubés en établissant une analogie avec les étudiants de Harvard : ces derniers réussissent-ils grâce à la formation dispensée par l'établissement ou est-ce uniquement parce que Harvard a sélectionné ceux qui étaient capables de réussir ? Il est possible de se poser la même question au sujet des entreprises qui sont soutenues par des structures d'incubation.

Dès lors, il semble très difficile de démontrer l'existence d'un impact intrinsèque des incubateurs sur les résultats des entreprises incubées. C'est pourquoi ce débat doit être délaissé en admettant qu'un effet positif existe, même s'il n'est pas toujours clairement mesurable au niveau des résultats financiers des entreprises. C'est clairement dans ce sens que va l'étude conduite par Lambrecht et Pirnay (2005). Celle-ci montre effectivement que les incubateurs n'ont pas d'impact direct sur les variables quantitatives telles que le chiffre d'affaires. En revanche, elle montre que les incubateurs ont malgré tout un effet positif qui se manifeste sur les variables qualitatives des entreprises incubées : meilleure organisation, plus grande capacité à faire face aux difficultés futures, développement du knowlegde management... Malgré les doutes sur le rôle que les incubateurs jouent dans les résultats financiers des entreprises, il semble difficile de nier leur impact sur les variables organisationnelles.

La problématique de l'impact des incubateurs est donc moins prégnante aujourd'hui et laisse davantage de place à des questions sur les différences de performance entre incubateurs qui sont pour la plupart financés par des fonds publics (Hackett et Dilts, 2004). Derrière ces questions se cache la volonté de mieux répartir les fonds en comparant le niveau de performance des incubateurs (Commission européenne, 2002), mais pour ce faire, encore faut-il savoir comment mesurer cette performance.

\subsection{Une performance multidimensionnelle}

La mesure de la performance des incubateurs ne fait pas réellement consensus dans la littérature (Phan, Siegel et Wright, 2005). Les études qui se sont intéressées à cette pro- 
blématique ne s'accordent pas sur le moyen de juger au mieux du succès de l'incubation parmi les différents critères qui ont été identifiés : nombre d'emplois créés, taux de survie des entreprises, développement d'innovations, accès des entrepreneurs à des réseaux... Ce manque de consensus n'est pas la seule limite dont souffre la littérature. Vanderstraeten et Matthyssens (2010) en soulignent deux autres. Premièrement, trop peu d'échelles ont été validées empiriquement pour mesurer la performance des incubateurs. La plupart des modèles de mesure développés dans la littérature ne reste effectivement qu'au stade de la proposition. Secondement, ces modèles de mesure oublient le plus souvent d'intégrer les accompagnants comme une variable de performance à mesurer. Or, ce sont ces accompagnants qui effectuent le lien entre les incubés et l'incubateur. Ils sont en quelque sorte les garants de la qualité des services fournis et devraient à ce titre être une des variables clés de tout modèle destiné à mesurer la performance des structures d'incubation. Une dernière autre limite peut enfin être identifiée, à savoir que les modèles de mesure proposés sont généralement fondés sur un seul type d'indicateur se rattachant à la même dimension de la performance des incubateurs (Schwartz et Göthner, 2009). Or, cela conduit nécessairement à une mesure incomplète, car les dimensions de la performance des incubateurs sont multiples et variées (Vanderstraeten et Matthyssens, 2010).

Parmi les principales dimensions identifiées dans la littérature, l'impact des incubateurs sur le développement économique local est de loin celui qui revient le plus souvent. Elle est appréhendée par des indicateurs tels que la création d'entreprises, la création d'emplois, la pérennité des entreprises, la croissance de leur chiffre d'affaires... (Cooper, 1985 ; Plosila et Allen, 1985 ; Allen et Levine, 1986 ; Hisrich et Smilor, 1988 ; Allen et Bazan, 1990 ; Lyons, 1990 ; Markley et McNamara, 1995 ; Molnar et al., 1997 ; Lalkaka et Abetti, 1999 ; Sherman, 1999; Lofsten et Lindelof, 2001, 2002 ; Lalkaka, 2003 ; Ferguson et Olofsson, 2004 ; Rothaermel et Thursby, 2005 ; Barbero, Casillas, Ramos et Guitar, 2012).

Mais, d'autres dimensions sont également très prégnantes dans la littérature. L'une d'entre elles renvoie à la qualité des services proposés par les incubateurs (Autio et Kloftsen, 1998 ; Peters, Rice et Sundarajan, 2004 ; Colbert, 2007). La norme NF de services NF X 50-770, révisée en 2003, précise le rôle des pépinières d'entreprises (Afnor, 1997). Ces dernières doivent ainsi assurer l'hébergement, les services et l'accompagnement. La norme prévoit plus précisément une sélection des projets, un appui à la création et au démarrage et une insertion dans l'environnement. Concrètement, cela se traduit par : l'accueil et l'orientation, la mise à disposition de locaux à des tarifs préférentiels, le partage d'une logistique commune (salle de réunion, technologies de l'information et de la communication (TIC), service postal, secrétariat, les conseils généralistes, l'évaluation des besoins en matière de formation, l'appui avant-création, l'assistance pendant le démarrage de l'activité, le suivi de l'entreprise, l'animation collective, l'aide à l'installation post-pépinière, c'est-à-dire après un hébergement maximum de 48 mois. Les incubateurs doivent ainsi proposer des services suffisamment nombreux et surtout un accompagnement adapté aux besoins des incubés (Cuzin et Fayolle, 2004). Une autre dimension importante est relative à la capacité des incubateurs à mettre en relation les incubés avec divers réseaux (Sherman et Chappell, 1998 ; Colombo et Delmastro, 2002 ; Haapasalo et Ekholm, 2004 ; Pena, 2004 ; Bollingtoft et Ulhoi, 2005 ; Carayannis et Von Zedtwitz, 2005 ; Chan et Lau, 2005 ; Hughes, Ireland et Morgan, 2007 ; Saleilles, 2007 ; Hackett et Dilts, 2008). Cette mise en relation a pour objectif de faciliter l'accès des incubés aux ressources dont ils ont besoin pour le développement de leur projet et notamment à des ressources financières (Redis, 2006). 
L’aspect réputationnel est aussi une composante clé de la performance des incubateurs, puisque nombreux sont les entrepreneurs qui rejoignent des structures d'incubation uniquement afin de bénéficier de la réputation de ces dernières (Studdard, 2006).

Cela ne doit cependant pas occulter qu'une des dimensions fondamentales de la performance des incubateurs reste malgré tout le transfert de connaissances nouvelles aux entrepreneurs (Cooper, 1985 ; Lichtenstein, 1992 ; Rice, 1993 ; Autio et Kloftsen, 1998 ; Rice, 2002 ; Rothaermel et Thursby, 2005 ; Becker et Gassmann, 2006). Une des missions essentielles des incubateurs est en effet de combler le manque de connaissances en gestion des entrepreneurs, car c'est l'une des principales causes de défaillance des jeunes entreprises. Cela passe par la proposition de formations aux incubés (Lévy-Tadjine, 2004), ainsi que par des accompagnants qui jouent un rôle de formateur au travers des conseils qu'ils apportent (Dokou, Baudoux et Roge, 2000). Ces derniers doivent également apporter un soutien moral aux incubés lorsque ceux-ci traversent des phases de doute (Valéau, 2006). Cet aspect de la performance est très dépendant des niveaux de compétence et d'expérience des accompagnants qui doivent par conséquent eux aussi être évalués (Rice et Matthews, 1995 ; Clarysse, Wright, Lockett, Van de Velde et Vohora, 2005 ; Fayolle, 2004 ; Versino et Hoeser, 2005). Afin de maximiser compétence et expérience, il est important de prendre conscience de la nécessité d'un système d'information adapté afin de faciliter l'échange de bonnes pratiques et le partage d'informations au sein de l'organisation. Ces actions permettront, en outre, de conserver des effectifs stables, de renforcer le degré d'innovation et la qualité du management des incubateurs (Mian, 1997 ; Bearse, 1998 ; Matt et Tang, 2010 ; Arlotto, 2012), et d'augmenter le niveau de qualification, le dynamisme et la capacité d'apprentissage des accompagnants (Rice et Matthews, 1995 ; Versino et Hoeser, 2005). Le management et l'apprentissage organisationnel des incubateurs constituent donc une dernière composante clé de leur performance.

Cette analyse de la littérature fait clairement apparaître le caractère multidimensionnel de la performance des structures d'incubation. Vanderstraeten et Matthyssens (2010) proposent de synthétiser ces multiples dimensions en deux principaux types de mesure : l'une centrée sur les objectifs des incubateurs et l'autre sur les processus internes d'incubation. Pour être à la fois complète et pertinente, l'appréciation de la performance des incubateurs ne peut occulter l'une ou l'autre de ces mesures. Par conséquent, il s'avère primordial de trouver un moyen de les combiner simultanément dans un même modèle.

\subsection{Proposition d'un modèle de mesure fondé sur le balanced scorecard}

Pour permettre une avancée dans la recherche sur la mesure de la performance des incubateurs, Messeghem, Naro et Sammut (2010) ont montré l'intérêt de s'appuyer sur le modèle du balanced scorecard développé par Kaplan et Norton $(1998,2001)$. Cet intérêt réside dans le fait que le balanced scorecard permet de regrouper dans un même modèle les deux visions différentes du contrôle de gestion que Simons (1995) appelle contrôle diagnostic et contrôle interactif. La première vision repose sur un contrôle a posteriori où l'on compare les résultats de l'organisation par rapport aux objectifs fixés. La seconde vision porte sur les processus mis en œuvre au sein de la structure en cherchant notamment à favoriser l'apprentissage organisationnel. 
Tableau 1. Adaptation du balanced SCORECARD (BSC) À LA Mesure des incubateurs

\begin{tabular}{|c|c|c|c|}
\hline Axes du BSC & Adaptation & Mesures & Littérature \\
\hline Axe financier & $\begin{array}{l}\text { Axe } \\
\text { développement } \\
\text { économique et } \\
\text { social }\end{array}$ & $\begin{array}{l}\text { Indicateurs } \\
\text { permettant de } \\
\text { juger de l'atteinte } \\
\text { ou non des } \\
\text { objectifs fixés avec } \\
\text { les financeurs }\end{array}$ & $\begin{array}{l}\text { Cooper (1985) ; Plosila } \\
\text { et Allen (1985); Allen et } \\
\text { Levine (1986) ; Hisrich et } \\
\text { Smilor (1988); Allen et } \\
\text { Bazan (1990); Lyons (1990); } \\
\text { Markley et McNamara (1995); } \\
\text { Mian (1997) ; Molnar et al. } \\
\text { (1997) ; Lalkaka et Abetti } \\
\text { (1999) ; Sherman (1999); } \\
\text { Lofsten et Lindelof (2001, } \\
\text { 2002) ; Colombo et Delmastro } \\
\text { (2002); Lalkaka (2003); } \\
\text { Ferguson et Olofsson (2004); } \\
\text { Rothaermel et Thursby } \\
\text { (2005) ; Barbero et al. (2012) }\end{array}$ \\
\hline Axe clients & Axe incubés & $\begin{array}{l}\text { Indicateurs } \\
\text { permettant } \\
\text { d'apprécier le lien } \\
\text { entre l'incubateur } \\
\text { et ses incubés }\end{array}$ & $\begin{array}{l}\text { Autio et Kloftsen (1998); } \\
\text { Cuzin et Fayolle (2004); } \\
\text { Peters, Rice et Sundarajan } \\
\text { (2004) ; Lambrecht et Pirnay } \\
\text { (2005) ; Studdard (2006); } \\
\text { Colbert (2007) }\end{array}$ \\
\hline Axe processus & $\begin{array}{l}\text { Axe processus } \\
\text { d'incubation }\end{array}$ & $\begin{array}{l}\text { Indicateurs } \\
\text { permettant } \\
\text { de mesurer } \\
\text { l'efficacité des } \\
\text { processus internes } \\
\text { d'incubation }\end{array}$ & $\begin{array}{l}\text { Cooper (1985) ; Lichtenstein } \\
\text { (1992); Rice (1993) ; Autio } \\
\text { et Kloftsen (1998); Sherman } \\
\text { et Chappell (1998) ; Colombo } \\
\text { et Delmastro (2002); } \\
\text { Rice (2002) ; Haapasalo } \\
\text { et Ekholm (2004) ; Pena } \\
\text { (2004) ; Bollingtoft et Ulhoi } \\
\text { (2005); Chan et Lau (2005); } \\
\text { Rothaermel et Thursby } \\
\text { (2005) ; Becker et Gassmann } \\
\text { (2006) ; Redis (2006) ; Valéau } \\
\text { (2006) ; Hughes, Ireland et } \\
\text { Morgan (2007); Saleilles } \\
\text { (2007) ; Hackett et Dilts } \\
\text { (2008) }\end{array}$ \\
\hline $\begin{array}{l}\text { Axe } \\
\text { apprentissage }\end{array}$ & Axe apprentissage & $\begin{array}{l}\text { Indicateurs } \\
\text { permettant } \\
\text { de piloter } \\
\text { l'apprentissage } \\
\text { au sein de } \\
\text { l'incubateur }\end{array}$ & $\begin{array}{l}\text { Rice et Matthews (1995); } \\
\text { Mian (1997) ; Bearse (1998); } \\
\text { Clarysse et al. (2005) ; Fayolle } \\
\text { (2004); Versino et Hoeser } \\
\text { (2005); Matt et Tang (2010); } \\
\text { Arlotto (2012) }\end{array}$ \\
\hline
\end{tabular}


Par conséquent, l'utilisation du balanced scorecard pour appréhender la performance des incubateurs permet de concilier les deux types de mesure identifiés par Vanderstraeten et Matthyssens (2010). La première mesure qui porte sur l'atteinte des objectifs correspond en effet au contrôle diagnostic, alors que la seconde mesure qui s'intéresse aux processus internes d'incubation renvoie au contrôle interactif.

Le balanced scorecard permet cette conciliation, car il se compose de plusieurs axes de performance qui s'articulent autour d'une vision stratégique (Kaplan et Norton, 1998 et 2001 ; Kaplan, 2008). Plus précisément, quatre axes de performance sont retenus : l'axe financier, l'axe clients, l'axe processus internes et l'axe apprentissage. L'objectif de cette approche est de ne plus se limiter à une mesure de la performance uniquement fondée sur des critères financiers. Si ces derniers sont toujours présents dans le balanced scorecard au travers de l'axe financier, ils ne sont toutefois plus considérés comme les seuls éléments de performance à prendre en compte. Il n'est plus seulement question de déterminer si les attentes des actionnaires ont été satisfaites (axe financier), mais aussi de savoir si celles des clients les ont été (axe clients), notamment par le biais de processus qui apportent de la valeur (axe processus) et d'une implication des ressources humaines qui favorise l'apprentissage organisationnel (axe apprentissage). L'utilisation du balanced scorecard permet également de favoriser le travail en réseau et le développement de partenariats avec d'autres organisations (Kaplan, Norton et Rugelsjoen, 2010).

Par conséquent, le balanced scorecard conduit à une mesure à la fois multidimensionnelle et équilibrée grâce à la prise en compte de plusieurs axes de performance. Son utilisation dans le contexte de l'incubation permet non seulement de concilier mesure des objectifs et mesure des processus, mais également d'appréhender toutes les facettes de la performance des incubateurs. Une réponse aux deux principaux défis rencontrés pour mesurer la performance de ces structures est donc apportée. Néanmoins, une utilisation réellement pertinente du balanced scorecard n'est possible qu'avec son adaptation aux spécificités de l'incubation.

Si cette première partie a permis de montrer comment le balanced scorecard peut constituer une réponse efficace aux principaux enjeux de la mesure de la performance des incubateurs, une limite précédemment évoquée demeure. En effet, la mobilisation du balanced scorecard n'est pour l'heure encore qu'une simple proposition. Or, il a été montré dans cette partie que le manque de validation empirique des modèles proposés pour mesurer la performance des incubateurs reste une des grandes limites de la littérature. Pour remédier à cette lacune, la partie suivante va exposer la méthodologie retenue afin de vérifier empiriquement la pertinence d'un modèle de mesure fondé sur le balanced scorecard.

\section{MÉTHODOLOGIE}

La méthodologie définie pour cette recherche combine à la fois des approches qualitatives et quantitatives. Elle peut être décomposée en quatre étapes. Premièrement, une étude en ligne a été conduite auprès de 21 responsables d'incubateur français qui se sont exprimés sur les principaux enjeux liés à la mesure de la performance des incubateurs. Les résultats de cette première étude ont servi à élaborer des guides d'entretien.

Deuxièmement, ces guides d'entretien ont été utilisés pour mener une étude qualitative exploratoire fondée sur des entretiens semi-directifs d'une à deux heures auprès de 4 financeurs 
et 6 responsables d'incubateurs. Ces entretiens ont tous été retranscrits et une analyse de contenu a été effectuée. De cette manière, un certain nombre d'indicateurs jugés comme étant pertinents pour appréhender la performance des incubateurs ont été identifiés et un premier modèle de mesure a été élaboré. Celui-ci est donc directement issu de la vision de deux catégories d'acteurs : les responsables d'incubateur et les financeurs. Le choix de n'interroger que ces deux catégories d'acteurs se justifie par la volonté de développer un outil se destinant au management des incubateurs. Malgré tout, il nous est apparu par la suite nécessaire d'interroger également des porteurs de projet, car ils constituent une autre partie prenante importante de l'incubation. Par conséquent, nous avons réalisé a posteriori 4 nouveaux entretiens auprès de porteurs de projet ayant été accompagnés par des incubateurs. Ces entretiens ont eux aussi donné lieu à une retranscription, puis à une analyse de contenu. Cette nouvelle analyse a permis de vérifier que l'ensemble des indicateurs de performance jugés pertinents par les porteurs de projet était déjà intégré dans le modèle de mesure initialement développé à partir des entretiens auprès des responsables d'incubateur et des financeurs. À l'issue de cette deuxième étape de recherche, un premier modèle de mesure de la performance des incubateurs est ainsi proposé. Il recouvre la vision des trois principales parties prenantes.

Troisièmement, une réunion de groupe avec des experts a été organisée et a mobilisé un financeur, un responsable d'incubateur et un responsable de réseau d'incubateurs. Cette troisième étape a été cruciale dans notre processus de recherche, car elle a permis de répondre à un double objectif : la définition par les acteurs de l'incubation d'une vision stratégique et la validation de l'intérêt d'un modèle de mesure de la performance fondé sur le balanced scorecard. Ainsi, une première partie de la réunion collective a été consacrée à la discussion et à la codéfinition par les responsables d'incubateur et les financeurs d'une vision stratégique pour les structures d'incubation, à savoir la contribution au développement économique local par la création d'entreprises pérennes. Il a été décidé de placer cette vision stratégique au cœur du balanced scorecard avec un axe qui y est entièrement dédié (axe développement économique et social). La seconde partie de la réunion a ensuite été consacrée à la discussion du modèle de mesure de la performance développé au cours de la précédente étape de recherche. Cette discussion a porté à deux niveaux : le choix des indicateurs de performance à retenir et la pertinence de classer ces derniers dans un modèle fondé sur le balanced scorecard. La validation par les acteurs mêmes de l'incubation de l'intérêt du balanced scorecard est déterminante, car cet outil ne s'adapte pas à tous les contextes. En effet, Oriot et Misiaszek (2012) montrent par exemple que le balanced scorecard n'est pas adapté aux PME en situation de redressement. Néanmoins, après quatre heures de discussion, la réunion de groupe organisée a permis aux acteurs présents de valider l'intérêt de recourir au balanced scorecard et de s'assurer que celuici est adapté au contexte des incubateurs. Les acteurs ont alors ensuite eux-mêmes classé 44 indicateurs dans un second modèle de mesure de la performance reprenant les quatre axes du balanced scorecard. Chacun de ces quatre axes a été redécoupé en trois dimensions. Ce modèle de mesure de la performance des incubateurs est présenté en annexe 1.

Quatrièmement, une étude quantitative a été conduite afin de vérifier empiriquement la pertinence du modèle développé. Pour ce faire, un questionnaire en ligne a été mis en place. Il a eu pour but de tester la pertinence de chacun des 44 indicateurs de performance retenus auprès de responsables d'incubateur. Ces derniers ont pu juger de cette pertinence au travers d'échelles de Likert en 5 points, allant de « $1:$ pertinence très faible » à « $5:$ pertinence très forte ». Le choix des répondants est en lien avec l'objectif de cette contribution : développer un outil de 
pilotage de la performance des incubateurs. Nous avons donc décidé de tester la pertinence de cet outil auprès des acteurs qui en feront l'usage, à savoir les responsables d'incubateur.

Par le biais de ce questionnaire en ligne, ce sont 109 responsables d'incubateur français qui se sont finalement exprimés. L'échantillon de cette étude se révèle être particulièrement important au regard de la population limitée de répondants potentiels, ainsi qu'en comparaison des études passées ayant interrogé par questionnaire des responsables d'incubateur. En effet, dans la plupart de ces études, les échantillons ne dépassent que très rarement les 100 répondants. À titre d'exemples, Becker et Gassmann (2006) ont interrogé dans leur étude 77 responsables d'incubateur, tandis que Hackett et Dilts (2008) en ont questionné 53 et que Barbero et al. (2012) en ont consulté 70. Si dans ce nouveau travail l'échantillon des répondants est sensiblement plus important que dans les précédents travaux, cela est en grande partie dû à l'aide apportée dans la distribution du questionnaire en ligne par les trois partenaires associés à cette recherche. Deux réseaux différents d'incubateurs oeuvrant dans le Sud de la France ont permis une forte diffusion régionale du questionnaire en ligne ; l'Agence pour la création d'entreprise $(\mathrm{APCE})^{1}$ a permis à cette étude de bénéficier d'un rayonnement national en diffusant le questionnaire à l'ensemble des incubateurs français qui travaillent avec cette agence.

Tous les incubateurs qui ont participé à cette étude quantitative sont incubateurs publics. Cela s'explique par une conception européenne de l'incubation qui diffère de celle nord-américaine (Aernoudt, 2004). Alors que l'incubation des projets de création d'entreprise est principalement assurée en Amérique du Nord par incubateurs privés, ce n'est pas le cas en Europe où cela est le plus souvent l'affaire d'incubateurs publics sans but lucratif. De plus, l'étude s'est concentrée sur les incubateurs de type généraliste qui accompagnent des projets « classiques ». Ce choix s'explique par la volonté de collecter des réponses comparables et de développer un premier outil de pilotage qui s'adresse aux structures les plus fréquemment rencontrées. Au final, ce sont 109 incubateurs français qui ont participé à cette étude. Ces structures sont de taille assez réduite, puisqu'elles emploient en moyenne 3,5 salariés.

Dans les résultats qui vont suivre, c'est uniquement sur cette quatrième et dernière étape de recherche que l'intérêt va se porter. Les 109 réponses collectées au travers du questionnaire en ligne ont été traitées par des analyses en composantes principales (ACP). Celles-ci ont été effectuées par le biais du logiciel SPSS. Le but de ces traitements statistiques est de tester la pertinence du modèle de mesure développé en vérifiant la composition de chaque axe de performance en termes de dimensions et d'indicateurs. Autrement dit, il s'agit de vérifier si les 44 indicateurs identifiés au travers des précédentes étapes de recherche se répartissent bien en trois dimensions sur les quatre axes de performance, conformément à ce qui a été anticipé dans le modèle de mesure présenté en annexe 1.

Des analyses en composantes principales ont donc été menées sur chacun des quatre axes de performance. L'indice KMO a été systématiquement calculé afin de vérifier que ces analyses étaient appropriées aux données collectées (indice KMO au moins égal à 0,5 ). Cet indice permet de déterminer si les corrélations existantes sont suffisantes pour réaliser une analyse factorielle. Une fois cette vérification effectuée sur les quatre axes de performance, la conduite de plusieurs ACP successives, en retenant une rotation Varimax, a permis d'épurer les données.

1 Organisme national chargé de la promotion et du développement de l'entrepreneuriat en France. 
Nous nous sommes ici inspirés du paradigme de Churchill en supprimant les indicateurs de performance qui ne pouvaient être clairement rattachés à une dimension. Cela nous a conduits à supprimer les indicateurs n'ayant pas de poids factoriel supérieur à 0,5 sur une des composantes principales et ceux ayant une communalité inférieure à 0,4 (Carricano et Poujol, 2008).

\section{RÉSULTATS}

Les résultats des analyses en composantes principales sont présentés pour chacun des quatre axes composant le modèle de mesure de la performance des incubateurs.

\subsection{Performance en termes de développement économique et social (axe 1)}

Le premier axe correspond à la performance pour les parties prenantes. Il s'exprime en termes de développement économique et social et se compose de 11 indicateurs qui ont été épurés au travers d'analyses en composantes principales. Celles-ci s'avèrent pertinentes pour analyser l'axe 1 étant donné que l'indice KMO est de 0,597 (supérieur à 0,5). Sur cet axe, trois composantes principales, qui expliquent $56,007 \%$ de la variance, sont validées.

Tableau 2. Résultats de l'ACP finale pour l'AXe 1

\begin{tabular}{|c|c|c|c|c|}
\hline & \multicolumn{3}{|c|}{ Composante } & \multirow[t]{2}{*}{ Communalité } \\
\hline & 1 & 2 & 3 & \\
\hline \multicolumn{5}{|l|}{ 1. Financeurs } \\
\hline Nombre d'emplois dans les entreprises créées & ,803 & & & ,669 \\
\hline Taux de pérennité des entreprises créées & 666 & & & ,446 \\
\hline $\begin{array}{l}\text { Développement des compétences des } \\
\text { entrepreneurs }\end{array}$ &, 587 & & & ,402 \\
\hline \multicolumn{5}{|l|}{ 2. Entrepreneurs } \\
\hline Revenus des entrepreneurs & & ,760 & &, 665 \\
\hline Accompagnement du deuil des projets échoués & & ,684 & &, 594 \\
\hline CA prévisionnel/CA réalisé & &, 586 & &, 581 \\
\hline Retour à l'emploi des entrepreneurs & &, 516 & & ,399 \\
\hline \multicolumn{5}{|l|}{ 3. Incubateurs } \\
\hline Nombre de projets incubés & & & 850 & ,743 \\
\hline Nombre de créations/Nombre de projets incubés & & & ,691 & ,542 \\
\hline $\begin{array}{l}\text { Somme des carrés des facteurs retenus pour la } \\
\text { rotation }\end{array}$ & 1,764 & 1,723 & 1,554 & \\
\hline Pourcentage de variance expliquée & 19,598 & 19,147 & 17,262 & \\
\hline Pourcentages cumulés & 19,598 & 38,745 & 56,007 & \\
\hline
\end{tabular}

Méthode d'extraction : analyse en composantes principales. Méthode de rotation : Varimax avec normalisation de Kaiser. La rotation a convergé en 5 itérations. 
Au travers du processus d'épuration des données par ACP successives, deux indicateurs de performance ont été supprimés : le nombre d'accompagnants au sein de l'incubateur et le montant du budget de l'incubateur. Ces deux indicateurs ont été retirés en raison de communalités trop faibles (respectivement de 0,234 et 0,302), c'est-à-dire d'une qualité de représentation pas assez satisfaisante (inférieure à 0,4 ). Conformément aux recommandations de Hair, Tatham, Anderson et Black (1998), les indicateurs se regroupant ensemble ont été examinés afin de déterminer et de nommer les trois facteurs qui les relient. Ainsi, la première composante regroupe des indicateurs renvoyant aux attentes des financeurs en termes de développement économique et social. L'indicateur relatif au développement des compétences des entrepreneurs s'est toutefois ajouté à cette dimension par rapport à ce qui était attendu. Pour les répondants, cet indicateur renvoie davantage à une attente des financeurs que des entrepreneurs eux-mêmes. La deuxième composante rassemble des indicateurs qui correspondent eux clairement aux attentes que peuvent avoir les entrepreneurs qui rejoignent un incubateur (revenus, chiffre d'affaires, etc.). La troisième composante réunit des indicateurs relatifs aux objectifs des incubateurs en termes d'impact et d'efficacité de leur action sur le développement économique et social (nombre de projets incubés et taux de conversion en entreprises créées).

\subsection{Performance liée aux incubés (axe 2)}

L'analyse du deuxième axe de performance relatif aux incubés porte sur 7 indicateurs. Avec un indice KMO de 0,604, l'analyse en composantes principales s'avère pertinente pour étudier cet axe de performance. Elle a ainsi permis de dégager trois composantes principales qui expliquent $66,602 \%$ de la variance.

Tableau 3. Résultats de l'ACP finale Pour l’axe 2

\begin{tabular}{|c|c|c|c|c|}
\hline & \multicolumn{3}{|c|}{ Composante } & \multirow[t]{2}{*}{ Communalité } \\
\hline & 1 & 2 & 3 & \\
\hline \multicolumn{5}{|l|}{ 1. Relations avec les incubés } \\
\hline Taux de satisfaction des incubés & ,808 & & & 692 \\
\hline Maintien d'un lien après la création d'entreprise & ,761 & & &, 640 \\
\hline \multicolumn{5}{|l|}{ 2. Image de l'incubateur } \\
\hline Utilisation d'outils de communication & &, 841 & & ,776 \\
\hline Notoriété de l'incubateur & &, 770 & & 695 \\
\hline \multicolumn{5}{|l|}{ 3. Attraits des services proposés } \\
\hline Mention des financeurs des services proposés & & & 872 & ,761 \\
\hline $\begin{array}{l}\text { Mention des réseaux professionnels accessibles au } \\
\text { travers de l'incubateur }\end{array}$ & & & ,601 & ,433 \\
\hline $\begin{array}{l}\text { Somme des carrés des facteurs retenus pour la } \\
\text { rotation }\end{array}$ & 1,374 & 1,368 & 1,254 & \\
\hline Pourcentage de variance expliquée & 22,899 & 22,808 & 20,896 & \\
\hline Pourcentages cumulés & 22,899 & 45,707 & 66,602 & \\
\hline
\end{tabular}

Méthode d'extraction : analyse en composantes principales. Méthode de rotation : Varimax avec normalisation de Kaiser. La rotation a convergé en 5 itérations. 
Suite à l'épuration des données, un seul indicateur de performance a été supprimé : la mise à disposition de documents formalisant les services d'incubation proposés. Cette suppression est due à une mauvaise qualité de représentation $(0,358)$. Les indicateurs restants ont été analysés afin de préciser les trois composantes sur lesquelles ils se regroupent (Hair et al., 1998). La première a trait aux relations entre l'incubateur et ses incubés que ce soit au niveau de la satisfaction de ces derniers ou de la pérennité de la relation entre les deux parties. La deuxième renvoie clairement à l'image de l'incubateur (communication et notoriété). La troisième est relative aux attraits des services proposés par l'incubateur aux entrepreneurs. Ces attraits sont assurés par la mention des financeurs des services et la mention des réseaux professionnels qui seront accessibles aux futurs incubés. Pour les répondants, ce dernier indicateur n'est donc pas à rattacher à la composante relative aux relations avec les incubés comme l’avait établi la précédente étude qualitative.

\subsection{Performance dans les processus d'incubation (axe 3)}

Le troisième axe de performance relatif aux processus d'incubation est composé de 13 indicateurs. L'indice KMO obtenu de 0,734 autorise le recours à l'analyse en composantes principales. Trois facteurs, qui expliquent $58,047 \%$ de la variance, ont été extraits.

TABleau 4. RÉSUltats de l’ACP Finale POUR L'AXe 3

\begin{tabular}{|c|c|c|c|c|}
\hline & \multicolumn{3}{|c|}{ Composante } & \multirow[t]{2}{*}{ Communalité } \\
\hline & 1 & 2 & 3 & \\
\hline \multicolumn{5}{|l|}{ 1. Processus de gestion de l'incubation } \\
\hline Mâtrise de la législation liée à la création d'entreprise & ,772 & & & ,640 \\
\hline Utilisation d'outils d'accompagnement & ,705 & & &, 523 \\
\hline Mise en relation avec des acteurs du réseau & 603 & & &, 502 \\
\hline Respect du cahier des charges &, 577 & & &, 542 \\
\hline Mise en place d'une démarche qualité &, 566 & & & ,498 \\
\hline \multicolumn{5}{|l|}{ 2. Processus de gestion des incubés } \\
\hline Animation active de l'incubation & &, 744 & & 603 \\
\hline Existence d'un bilan partagé post incubation & &, 739 & &, 551 \\
\hline $\begin{array}{l}\text { Apport de réponses sur mesure aux problématiques } \\
\text { des incubés }\end{array}$ & & ,690 & & 604 \\
\hline \multicolumn{5}{|l|}{ 3. Processus d'innovation } \\
\hline Engagement d'expérimentations au sein de l'incubateur & & &, 851 &, 728 \\
\hline $\begin{array}{l}\text { Participation à des réflexions collectives sur les } \\
\text { méthodes d'incubation }\end{array}$ & & & ,740 & 625 \\
\hline Somme des carrés des facteurs retenus pour la rotation & 2,298 & 2,298 & 1,858 & \\
\hline Pourcentage de variance expliquée & 20,888 & 20,267 & 16,892 & \\
\hline Pourcentages cumulés & 20,888 & 41,155 & 58,047 & \\
\hline
\end{tabular}

Méthode d'extraction : analyse en composantes principales. Méthode de rotation : Varimax avec normalisation de Kaiser. La rotation a convergé en 4 itérations. 
Le processus d'épuration des données a entrainé la suppression de deux indicateurs sur ce troisième axe de performance : l'accompagnement à distance et le respect de la confidentialité. La mauvaise qualité de leur représentation respective $(0,300$ et 0,373$)$ n'a pas permis de les maintenir dans l'analyse. Comme pour les deux premiers axes de performance, les indicateurs restants ont été examinés pour préciser les trois facteurs sur lesquels ils se regroupent (Hair et al., 1998). Le premier facteur rassemble cinq indicateurs et renvoie au processus de management de l'incubation (respect du cahier des charges, démarche qualité, etc.). Le deuxième facteur, qui regroupe quatre indicateurs, a trait au processus de gestion des incubés (animation active, bilan post incubation, etc.). Le troisième facteur, qui se compose des deux indicateurs attendus (expérimentations et réflexions sur les méthodes d'incubation), correspond au processus d'innovation au sein de l'incubateur.

\subsection{Performance en termes d'apprentissage (axe 4)}

Le quatrième axe de performance est relatif à l'apprentissage au sein de l'incubateur. En termes de nombre d'indicateurs, ce dernier axe est le plus important des quatre composant le modèle de mesure, puisqu'il comprend 13 indicateurs. Après avoir vérifié que l'indice KMO est satisfaisant $(0,727)$, l'analyse en composantes principales a dégagé trois facteurs expliquant $63,737 \%$ de la variance.

Tableau 5. Résultats de l'ACP finale Pour l'axe 4

\begin{tabular}{|c|c|c|c|c|}
\hline & \multicolumn{3}{|c|}{ Composante } & \multirow[t]{2}{*}{ Communalité } \\
\hline & 1 & 2 & 3 & \\
\hline \multicolumn{5}{|l|}{ 1. Capital informationnel et relationnel } \\
\hline $\begin{array}{l}\text { Participation à des manifestations liées à l'incubation } \\
\text { et à la création d'entreprise }\end{array}$ & ,824 & & & ,681 \\
\hline Insertion de l'incubateur dans les réseaux locaux & ,765 & & & 602 \\
\hline Échange de bonnes pratiques entre incubateurs & ,750 & & & 654 \\
\hline $\begin{array}{l}\text { Repérage des acteurs locaux disposant des } \\
\text { compétences clés }\end{array}$ &, 629 & & & ,661 \\
\hline \multicolumn{5}{|l|}{ 2. Capital humain } \\
\hline Formation continue du personnel de l'incubateur & &, 807 & & ,710 \\
\hline $\begin{array}{l}\text { Utilisation de référentiels de compétences pour la } \\
\text { gestion du personnel }\end{array}$ & & 679 & &, 526 \\
\hline Polyvalence du personnel & & 652 & & ,432 \\
\hline $\begin{array}{l}\text { Expérience antérieure du personnel dans l'incubation } \\
\text { 3. Capital organisationnel }\end{array}$ & & ,618 & & ,638 \\
\hline Taux de rotation du personnel (Turnover) & & & ,904 & ,832 \\
\hline Somme des carrés des facteurs retenus pour la rotation & 2,342 & 2,215 & 1,180 & \\
\hline Pourcentage de variance expliquée & 26,021 & 24,608 & 13,108 & \\
\hline Pourcentages cumulés & 26,021 & 50,629 & 63,737 & \\
\hline
\end{tabular}

Méthode d'extraction : analyse en composantes principales. Méthode de rotation : Varimax avec normalisation de Kaiser. La rotation a convergé en 4 itérations. 
Au terme du processus d'épuration des données, quatre indicateurs ont été supprimés sur le dernier axe de performance : système d'information adapté à l'incubateur, spécialisation du personnel de l'incubateur, réalisation d'une veille informationnelle et recours à un management en équipes. Les deux premiers ont été retirés en raison de leur faible qualité de représentation (respectivement 0,378 et 0,309). Les deux suivants ont été éliminés, car il n'a pas été possible de les rattacher clairement à une seule composante. En effet, ces indicateurs ont eu des poids factoriels très proches de 0,5 simultanément sur les composantes 1 et 2 (respectivement 0,493 et 0,498 pour la veille informationnelle ; 0,460 et 0,535 pour le management en équipes). Les recommandations de Hair et al. (1998) ont été une nouvelle fois suivies, puisque les indicateurs restants ont été analysés afin de préciser les trois facteurs sur lesquels ils se rassemblent. Le premier facteur regroupe des indicateurs qui renvoient au capital informationnel et relationnel de l'incubateur (participation à diverses manifestations, insertion dans les réseaux locaux, etc.). Le deuxième facteur rassemble des indicateurs qui ont trait au capital humain de l'incubateur (formation continue du personnel, utilisation de référentiels de compétences et polyvalence du personnel). Le troisième facteur n'est enfin composé que d'un seul indicateur, à savoir le taux de rotation du personnel (turnover). Ce dernier facteur renvoie donc au capital organisationnel de l'incubateur.

\section{DISCUSSION}

Pour être pertinente, la mesure de la performance des incubateurs doit être multidimensionnelle (Vanderstraeten et Matthyssens, 2010). C'est la raison pour laquelle le modèle de mesure développé dans ce travail est composé de quatre axes principaux qui ont été chacun découpés en trois dimensions. De cette manière, la plupart des déterminants de la performance des incubateurs sont pris en compte au travers d'un total de 12 dimensions différentes. Les analyses en composantes principales effectuées sur les 109 réponses collectées grâce au questionnaire en ligne permettent de valider la pertinence de ce modèle de mesure. En effet, toutes les dimensions qui le composent sont vérifiées empiriquement, même si tous les indicateurs de performance initialement identifiés ne sont pas conservés. La mauvaise qualité de représentation a été la principale raison de la suppression de certains indicateurs. Ce résultat peut essentiellement s'expliquer par le caractère exploratoire de cette recherche.

Les 12 dimensions du modèle de mesure validées par le biais de l'étude quantitative se retrouvent pour la plupart dans la littérature. Néanmoins, elles n'avaient pas été jusqu'à présent suffisamment agrégées. Nous y remédions dans cette publication, puisque trois premières dimensions sont synthétisées au sein d'un premier axe principal : le développement économique et social (Colombo et Delmastro, 2002 ; Ferguson et Olofsson, 2004 ; Rothaermel et Thursby, 2005 ; Barbero et al., 2012). Ces trois premières dimensions correspondent chacune au point de vue de l'une des trois principales parties prenantes : incubateurs, entrepreneurs et financeurs. Chaque angle de vue entraîne des indicateurs de développement économique et social différents. Un deuxième axe regroupe trois autres dimensions de la performance des incubateurs qui sont reliées aux incubés (Cuzin et Fayolle, 2004 ; Peters, Rice et Sundarajan, 2004 ; Lambrecht et Pirnay, 2005 ; Studdard, 2006). La première d'entre elles renvoie à l'attrait des services proposés par l'incubateur aux incubés potentiels. La deuxième correspond aux relations entre l'incubateur et ses incubés. La dernière est liée à l'image globale de l'incubateur. Un troisième axe permet d'agréger encore trois autres composantes 
de la performance des incubateurs qui sont toutes relatives aux processus en œuvre au sein des incubateurs : processus de gestion de l'incubation, processus de gestion des incubés et processus d'innovation (Chan et Lau, 2005 ; Becker et Gassmann, 2006 ; Hughes, Ireland et Morgan, 2007 ; Saleilles, 2007 ; Hackett et Dilts, 2008). Avec un total de 11 indicateurs validés au sein de cet axe, celui-ci se révèle être le plus riche du modèle de mesure. Trois dernières dimensions sont enfin synthétisées dans un quatrième et dernier axe de performance qui renvoie à l'apprentissage de l'incubateur (Clarysse et al., 2005 ; Fayolle, 2004 ; Versino et Hoeser, 2005 ; Matt et Tang, 2010). Cet apprentissage est appréhendé au travers de trois niveaux différents de capital : le capital humain, le capital informationnel et relationnel et le capital organisationnel. Cependant, les indicateurs se regroupent essentiellement sur les deux premières dimensions. La dernière relative au capital organisationnel est composée d'un seul indicateur : le taux de rotation du personnel.

Une synthèse de l'ensemble du modèle de mesure validé par le biais de cette recherche est proposée en annexe 2. Ce modèle se compose au final de 35 indicateurs de performance contre 44 initialement. Par conséquent, l'étude empirique a permis d'épurer le modèle en supprimant les indicateurs qui ne pouvaient être clairement rattachés à une des dimensions de la performance des incubateurs. Malgré cette épuration, le modèle reste relativement riche et doit permettre de dépasser les difficultés rencontrées par la littérature pour définir des critères de mesure pertinents, multidimensionnels et empiriquement validés (Phan, Siegel et Wright, 2005 ; Schwartz et Göthner, 2009). Alors que les précédents travaux occultaient presque systématiquement le rôle joué par les accompagnants dans la performance des incubateurs (Vanderstraeten et Matthyssens, 2010), la validation de ce nouveau modèle de mesure permet également de remédier à ce manquement. Dans ce modèle, les accompagnants sont évalués une première fois dans le troisième axe de performance relatif aux processus d'incubation par le biais de leur capacité à apporter des réponses pertinentes aux questions des incubés. Ils sont ensuite évalués une seconde fois dans le quatrième axe de performance relatif à l'apprentissage de l'incubateur au travers de leurs caractéristiques propres : compétence, expérience, niveau de polyvalence, etc.

Enfin, la validation de ce nouveau modèle pour appréhender la performance des incubateurs permet de concilier les deux types de mesure évoqués par Vanderstraeten et Matthyssens (2010) : une mesure centrée sur les objectifs et l'autre centrée sur les processus internes d'incubation. Dans ce modèle, le premier axe de performance permet d'apprécier l'atteinte des objectifs assignés aux incubateurs en termes de développement économique et social. Les troisième et quatrième axes renvoient à la mesure des processus d'incubation. Plus précisément, le troisième axe correspond à la mesure directe des processus, alors que le quatrième axe relatif à l'apprentissage permet d'apprécier les moyens mis en œuvre pour les améliorer : formation continue, développement des compétences, participation à des manifestations sur l'incubation, etc. Au final, le modèle validé doit permettre de conduire une mesure de la performance des incubateurs aussi complète que possible.

\section{CONCLUSION}

Les implications de cette recherche sont conceptuelles, méthodologiques et managériales. D’un point de vue conceptuel, une réponse a été apportée au défi de proposer un modèle 
multidimensionnel pour mesurer la performance des incubateurs grâce à la mobilisation du balanced scorecard. Celui-ci permet de concilier des indicateurs qualitatifs et quantitatifs fondés sur une mesure à la fois des résultats et des processus. D’un point de vue méthodologique, la démarche retenue pour construire ce modèle de mesure a combiné des approches qualitatives et quantitatives. Elle a permis de cette manière d'impliquer l'ensemble des parties prenantes concernées, à savoir les financeurs, les responsables d'incubateur et les porteurs de projet. Cette vision intégrative a conduit à multiplier les échanges avec ces différents acteurs qui se sont exprimés dans le cadre d'entretiens et d'enquêtes. D’un point de vue managérial, cette recherche peut être utile aux responsables d'incubateur qui disposent ainsi d'un outil de pilotage de la performance. En effet, ces responsables ont besoin d'informations relatives à la performance de leur structure pour être en mesure de prendre des décisions à la fois opérationnelles et stratégiques (Tornatzky, Sherman et Adkins, 2002). L'outil que nous avons développé sur les fondements du balanced scorecard peut jouer ce rôle et permettre ainsi de prendre certaines décisions relatives, par exemple, aux processus d'incubation (ajout ou suppression de certaines étapes d'incubation, renforcement de la mise en réseau des incubés, etc.) ou à la gestion du personnel (formation continue, recrutement d'accompagnants plus expérimentés, etc.). Il incombe aux responsables d'incubateur de renseigner et de tenir à jour l'outil pour que celui-ci leur soit réellement utile dans le pilotage de leur structure. L'outil suppose également la mise en place d'une enquête de satisfaction annuelle auprès des porteurs de projet incubés afin de collecter leur avis sur un certain nombre d'aspects de la performance des incubateurs (insertion dans des réseaux professionnels, pertinence des conseils apportés, adaptation du parcours d'incubation, etc.). En fonction des résultats, il sera alors possible pour les responsables d'incubateur de décider d'éventuelles actions correctrices.

Les limites de cette recherche sont principalement d'ordre méthodologique. Premièrement, lors de notre étude qualitative, tous les entretiens n'ont pas été réalisés au cours de la même période. Les entretiens auprès des porteurs de projet ont été effectués et analysés a posteriori. Les résultats ont été utilisés pour confirmer le choix des indicateurs retenus dans le modèle de mesure de la performance des incubateurs. Deuxièmement, si la taille de l'échantillon des répondants au questionnaire en ligne est relativement conséquente au regard des travaux antérieurs (109 responsables d'incubateur) et apporte certaines garanties de représentativité, il aurait pu être malgré tout intéressant de contrôler certaines variables telles que par exemple le niveau d'expérience des responsables d'incubateur. Enfin, troisièmement, notre étude quantitative s'est concentrée uniquement sur des incubateurs français. Or, il existe des divergences dans les pratiques d'incubation d'un pays à un autre (Aernoudt, 2004). Il pourrait donc être intéressant d'élargir le périmètre de la recherche en y intégrant des incubateurs situés dans différents pays. Une première piste de recherche future consisterait ainsi à mener une étude comparative internationale afin d'établir si la performance des incubateurs peut être mesurée de la même manière quel que soit le pays. D'autres perspectives de recherches existent également. Il serait possible de compléter l'étude quantitative que nous avons conduite auprès des responsables d'incubateur par d'autres études auprès des financeurs et des porteurs de projet. Cela permettrait de s'assurer quantitativement de la convergence des visions de la performance des incubateurs de l'ensemble des acteurs.

De futures recherches pourraient aussi adopter une approche contingente qui serait complémentaire à celle que nous avons retenue dans cette contribution. En effet, nous nous sommes 
attachés ici à développer un modèle type de mesure de la performance pour les incubateurs "généralistes ». C'est la raison pour laquelle nous nous sommes concentrés sur ces structures-ci. Toutefois, la littérature a relevé l'existence de plusieurs types d'incubateur (Albert, Bernasconi et Gaynor, 2003). Par conséquent, l'adoption d'une approche contingente pourrait conduire dans de futurs travaux à une adaptation de la mesure de la performance. Cela pourrait passer par une étude qualitative s'intéressant à la manière dont différents incubateurs implémentent et s'approprient l'outil de pilotage développé. Cette piste de recherche a déjà été initiée, puisque cinq incubateurs français expérimentent actuellement l'outil. Si les premiers éléments démontrent d'un réel intérêt des responsables d'incubateur pour ce dernier, les résultats doivent encore être affinés avant de pouvoir aboutir à une contextualisation de la mesure de la performance des incubateurs.

Annexe 1. Modèle de mesure de La PerformanCe Des incubateurs

\section{Axe 1 : développement économique et social}

\begin{tabular}{|c|c|c|}
\hline Incubateurs & Entrepreneurs & Financeurs \\
\hline $\begin{array}{l}\text { - Nombre d'accompagnants } \\
\text { au sein de l'incubateur }\end{array}$ & $\begin{array}{l}\text { - Développement des } \\
\text { compétences des entrepreneurs }\end{array}$ & $\begin{array}{l}\text { - Nombre d'emplois } \\
\text { dans les entreprises }\end{array}$ \\
\hline - Nombre de projets incubés & - Accompagnement du deuil & créées \\
\hline $\begin{array}{l}\text { - Nombre de créations/ } \\
\text { Nombre de projets incubés }\end{array}$ & $\begin{array}{l}\text { des projets échoués } \\
\text { - Revenus des entrepreneurs }\end{array}$ & $\begin{array}{l}\text { - Taux de pérennité } \\
\text { des entreprises créées }\end{array}$ \\
\hline - Montant du budget de & - CA prévisionnel/CA réalisé & \\
\hline l'incubateur & $\begin{array}{l}\text { - Retour à l'emploi des } \\
\text { entrepreneurs }\end{array}$ & \\
\hline
\end{tabular}

\section{Axe 2 : incubés}

\begin{tabular}{lll}
\hline Attraits des services proposés & Relations avec les incubés & Image de l'incubateur \\
- Mise à disposition de & - Taux de satisfaction & - Utilisation d'outils \\
documents formalisant & des incubés & de communication \\
les services d'incubation & - Mention des réseaux & - Notoriété de \\
- Mention des financeurs & professionnels accessibles & l'incubateur \\
des services proposés & au travers de l'incubateur & \\
& - Maintien d'un lien après & \\
& la création d'entreprise & \\
\hline
\end{tabular}

Axe 3 : processus d'incubation

\begin{tabular}{lll}
\hline $\begin{array}{l}\text { Processus de gestion } \\
\text { de l'incubation }\end{array}$ & $\begin{array}{l}\text { Processus de gestion } \\
\text { des incubés }\end{array}$ & Processus d'innovation \\
- Respect du cahier des charges & - Animation active de & - Participation à des \\
- Maîtrise de la législation & l'incubation & $\begin{array}{l}\text { réflexions collectives } \\
\text { sur les méthodes } \\
\text { liée à la création d'entreprise }\end{array}$ \\
$\begin{array}{ll}\text { - Utilisation d'outils } & \text { Existence d'un bilan partagé } \\
\text { d'accompagnement incubation }\end{array}$ &
\end{tabular}


- Mise en relation avec des acteurs du réseau

- Accompagnement à distance

- Mise en place d'une démarche qualité
- Apport de réponses sur mesure aux problématiques des incubés

- Respect de la confidentialité

- Adaptation de l'incubation à l'avancement des projets
- Engagement d'expérimentations au sein de l'incubateur

\section{Axe 4 : apprentissage au sein de l'incubateur}

\begin{tabular}{lll}
\hline Capital humain & $\begin{array}{l}\text { Capital informationnel/ } \\
\text { relationnel }\end{array}$ & Capital organisationnel \\
- Utilisation de référentiels & - Insertion de l'incubateur & - Recours à un \\
de compétences pour & dans les réseaux locaux & management en équipes \\
la gestion du personnel & - Système d'information & - Polyvalence du \\
- Formation continue du & adapté à l'incubateur & personnel \\
personnel de l'incubateur & - Réalisation d'une veille & - Spécialisation \\
- Expérience antérieure du & informationnelle & du personnel \\
personnel dans l'incubation & - Échange de bonnes pratiques & de l'incubateur \\
- Repérage des acteurs & entre incubateurs & - Taux de rotation du \\
locaux disposant & - Participation à des & personnel (Turnover) \\
des compétences clés & manifestations liées à & \\
& l'incubation et à la création & \\
& d'entreprise & \\
\hline
\end{tabular}

ANnexe 2. ModÈle de Mesure De LA PERFORMANCE DES INCUBATEURS APRÈS VALIDATION EMPIRIQUE

\section{Axe 1 : développement économique et social}

\begin{tabular}{lll}
\hline Incubateurs & Entrepreneurs & Financeurs \\
- Nombre de projets incubés & - Accompagnement du deuil & - Nombre d'emplois dans \\
- Nombre de créations/ & des projets échoués & $\begin{array}{l}\text { les entreprises créées } \\
\text { Nombre de projets incubés }\end{array}$ \\
& - Revenus des entrepreneurs & - Taux de pérennité \\
& - CA prévisionnel/CA réalisé & des entreprises créées \\
& - Retour à l'emploi & - Développement \\
& des entrepreneurs & des compétences \\
& & des entrepreneurs \\
\hline
\end{tabular}

\section{Axe 2 : incubés}

\begin{tabular}{lll}
\hline Attraits des services proposés & Relations avec les incubés & Image de l'incubateur \\
- Mention des financeurs & - Taux de satisfaction & - Utilisation d'outils \\
des services proposés & des incubés & de communication \\
- Mention des réseaux & - Maintien d'un lien après & - Notoriété de \\
professionnels accessibles & l'incubateur \\
au travers de l'incubateur & & \\
\hline
\end{tabular}


Axe 3 : processus d'incubation

Processus de gestion de l'incubation

- Respect du cahier des charges

- Maîtrise de la législation liée à la création d'entreprise

- Utilisation d'outils

d'accompagnement

- Mise en relation avec des acteurs du réseau

- Mise en place d'une démarche qualité
Processus de gestion des incubés

- Animation active de l'incubation

- Existence d'un bilan partagé post incubation

- Apport de réponses sur mesure aux problématiques des incubés

- Adaptation de l'incubation à l'avancement des projets
Processus d'innovation

- Participation à des réflexions collectives sur les méthodes d'incubation

- Engagement d'expérimentations au sein de l'incubateur

\section{Axe 4 : apprentissage au sein de l'incubateur}

\section{Capital humain}

- Utilisation de référentiels de compétences pour la gestion du personnel

- Formation continue du personnel de l'incubateur

- Polyvalence du personnel

- Expérience antérieure du personnel dans l'incubation

\section{Capital informationnel/ relationnel \\ Capital organisationnel \\ - Insertion de l'incubateur dans \\ - Taux de rotation du les réseaux locaux personnel (Turnover)}

- Échange de bonnes pratiques entre incubateurs

- Participation à des manifestations liées à l'incubation et à la création d'entreprise

- Repérage des acteurs locaux disposant des compétences clés

\section{RÉFÉRENCES}

AERnoudt, R. (2004). Incubators : tool for entrepreneurship ? Small Business Economics, 23(2), $127-$ 135 .

Aerts, K., Matthyssens, P. et Vandenbempt, K. (2007). Critical role and screening practices of European business incubators. Technovation, 27(5), 254-267.

Afnor (1997). Accompagnement de l'entreprise. Activités des pépinières d'entreprises. Norme NF X 50-770. Récupéré le 6 octobre 2014 sur le site : http://www.marque-nf.com/marquenf/argumentaires/ depliants/NF-service-pepinieres-d-entreprises.pdf.

Albert, P., Bernasconi, M. et Gaynor, G. (2003). Incubateurs et pépinières d'entreprises : un panorama international. Paris, L'Harmattan.

Allen, D. et Bazan, E. (1990). Value-added contribution of Pennsylvania's business incubators to ten- 
ant firms and local economies. Rapport présenté par le department du commerce de Pennsylvanie. État-Unis, Université d'État de Pennsylvanie.

Allen, D. et Levine, V. (1986). Nurturing advanced technology enterprises : emerging issues in state and local economic development policy. New York, Praeger.

Allen, D.N. et McCluskey, R. (1990). Structure, policy, services, and performance in the business incubator industry. Entrepreneurship, Theory and Practice, 15(2), 61-77.

Arlotto, J. (2012). Les performances des pépinières d'entreprises vues par les jeunes entrepreneurs accompagnés - une étude exploratoire (thèse de doctorat). Université de Corse-Pascal Paoli, Corte, France.

Arlotto, J., Sahut, J.-M. et. Teulon, F. (2011). What is the performance of incubators? The point of view of coached entrepreneurs. International Journal of Business, 16(4), 341-352.

Autio, E. et Klofsten, M. (1998). A comparative study of two european business incubators. Journal of Small Business Management, 36(1), 30-43.

Bakkali, C., Messeghem, K. et Sammut, S. (2013). Pour un outil de mesure et de pilotage de la performance des incubateurs. Management International, 17(3), 140-153.

Barbero, J.L., Casillas, J.C., Ramos, A. et. Guitar, S. (2012). Revisiting incubation performance, how incubator typology affects results. Technological Forecasting \& Social Change, 79(5), 888-902.

BeARSE, P. (1998). A question of evaluation : NBIA's assessment of business incubators. Economic Development Quarterly, 12(4), 322-333.

Becker, B. et Gassmann, O. (2006). Gaining leverage effects from knowledge modes within corporate incubators. R\&D Management, 36(1), 1-16.

Bergek, A. et Norrman, C. (2008). Incubator best practice : a framework. Technovation, 28(1-2), 20-28.

Bigliardi, B., Dormio, A.I., Nosella, A. et Petroni, G. (2006). Assessing science parks' performances : directions from selected italian case studies. Technovation, 26(4), 489-505.

BøLlingtoft, A. (2012). The bottom-up business incubator : leverage to networking and cooperation practices in a self-generated, entrepreneurial-enabled environment. Technovation, 32(5), 304-315.

BøLlingtoft, A. et. UlHøI, J.P. (2005). The networked business incubator-leveraging entrepreneurial agency? Journal of Business Venturing, 20(2), 265-290.

Carayannis, E.G. et. Von Zedtwitz, M. (2005). Architecting glocal (global-local), real-virtual incubator networks (G-RVINs) as catalysts and accelerators of entrepreneurship in transitioning and developing economies : lessons learned and best practices from current development and business incubation practices. Technovation, 25(2), 95-110.

Carricano, M. et Poujol, F. (2008). Analyse de données avec SPSS. Paris, Pearson Education.

Chabaud, D., Ehlinger, S. et Perret, V. (2004). Les pépinières et incubateurs dans l'accompagnement de la création d'entreprises. Dans C. Voisin, S. Ben Mahmoud-Jouini et S. Edouard (dir.), Les réseaux : dimensions stratégiques et organisationnelles (p. 215-227). Paris, Economica.

CHAN, K.F. et LAU, T. (2005). Assessing technology incubator programs in the science park : the good, the bad, and the ugly. Technovation, 25(10), 1215-1228. 
Clarysse, B., Wright, M., Lockett, A., Van de Velde, E. et Vohora, A. (2005). Spinning off new ventures : a typology of incubation strategies from european research institutions. Journal of Business Venturing, 20(2), 183-216.

Colbert, C. (2007). Practical guide to business incubator marketing. Athens, Ohio, NBIA Publications.

Colombo, M. et Delmastro, M. (2002). How effective are technology incubators? Evidence from Italy. Research Policy, 31(7), 1103-1122.

Commission Europeenne (2002). Benchmarking of business incubators. Rapport final. Bruxelles, Belgique.

Cooper, A.C. (1985). The role of incubator organizations in the founding of growth-oriented firms. Journal of Business Venturing, 1(1), 75-86.

Cuzin, R. et Fayolle, A. (2004). Les dimensions structurantes de l'accompagnement en création d'entreprise. La Revue des sciences de gestion : direction et gestion, 39(210), 77-88.

Dokou, G.A.K., Baudoux, M. et Rogé, M. (2000). L’accompagnement managérial et industriel de la PME : l'entrepreneur, l'universitaire et le consultant. Paris, L'Harmattan.

FAYOLLE, A. (2004). Compréhension mutuelle entre les créateurs d'entreprise et les accompagnateurs : une recherche exploratoire sur des différences de perception. Management international, 8(2), 1-14.

Ferguson, R. et Olofsson, C. (2004). Science parks and the development of NTBFs - location, survival and growth. Journal of Technology Transfer, 29(1), 5-17.

HaApasalo, H. et Eкhоlм, T. (2004). A profile of european incubators : a framework for commercialising innovations. International Journal of Entrepreneurship and Innovation management, 4(2-3), 248-270.

HacketT, S.M. et Dilts, D.M. (2004). A systematic review of business incubation research. Journal of Technology Transfer, 29(1), 55-82.

HacketT, S.M. et Dilts, D.M. (2008). Inside the black box of business incubation : study B-scale assessment, model refinement, and incubation outcomes. Journal of Technology Transfer, 33(5), 439-471.

Hair, J.F., TAtham, R.L., Anderson, R.E. et Black, W. (1998). Multivariate data analysis. Upper Saddle River, New Jersey, Prentice Hall.

HisRich, R. et SMILOR, R. (1988). The university and business incubation : technology, transfer through entrepreneurial development. Technology Transfer, 13(1), 14-19.

Hughes, M., Ireland, R.D. et Morgan, R.E. (2007). Stimulating dynamic value : social capital and business incubation as a pathway to competitive. Long Range Planning, 40(2), 154-177.

Kaplan, R.S. (2008). Conceptual foundations of the balanced scorecard. Dans C. Chapman, A. Hopwood, et M. Shields (dir.), Handbook of Management Accounting Research: 3 (p. 1207-1410). Oxford, Elsevier.

Kaplan, R.S. et Norton, D.P. (1998). Le tableau de bord prospectif. Paris, Éditions d'Organisation.

Kaplan, R.S. et Norton, D.P. (2001). Comment utiliser le tableau de bord prospectif. Paris, Éditions d'Organisation.

Kaplan, R.S., Norton, D.P. et Rugelsjoen, B. (2010). Managing alliances with the balanced scorecard. Harvard Business Review, 88(1), 114-120.

Kuratko, D.F. et. LaFollette, W.R. (1987). Small business incubators for local economic development. Economic Development Review, 5(2), 49-55. 
LALKAKA, R. (2003). Business incubators in developing countries : characteristics and performance. International Journal of Entrepreneurship and Innovation Management, 3(1-2), 31-55.

LalkaKa, R. et AвETTI, P. (1999). Business incubation and entreprise support system in restructuring countries. Business Incubation and Enterprise Support Systems, 8(3), 197-209.

Lambrecht, J. et Pirnay, F. (2005). An evaluation of public support measures for private external consultancies to SMEs in the walloon region of Belgium. Entrepreneurship \& Regional Development, 17(2), 89-108.

LÉVY-TADIINE, T. (2004). L'entrepreneuriat immigré et son accompagnement en France (thèse de doctorat en sciences de gestion). Université du Sud-Toulon-Var, France.

Lewis, D. (2001). Does technology incubation work? A critical assessment. Washington, D.C., Department of Commerce, Economic Development Administration.

Lewis, D. (2008). A guide to business incubation for New York elected officials. New York, NYSBIA, Albany.

Lichtenstein, G. (1992). The significance of relationships in entrepreneurship : a case study of ecology of enterprise in two business incubators (thèse de doctorat). Université de la Pennsylvanie, Philadelphie, État-Unis.

Lofsten, H. et Lindelof, P. (2001). Science parks in Sweden - industrial renewal and development. RßD Management, 31(3), 309-322.

Lofsten, H. et Lindelof, P. (2002). Science parks and the growth of new technology-based firms - academic industry links, innovation and markets. Research Policy, 31(6), 859-876.

LumpKin, J. et Ireland, R.D. (1988). Screening practices of new business incubators : the evaluation of critical success factors. American Journal of Small Business, 12(4), 59-81.

Lyons, T.S. (1990). Birthing economic development : how effective are Michigan's business incubators? (rapport de recherche). Université d'État du Michigan, East Lansing, Michigan, État-Unis.

Markley, D. et McNamara, K. (1995). Economic and fiscal impacts of a business incubators. Economic Development Quarterly, 9(3), 273-279.

Matt, M. et TANG, M.F. (2010). Management of university incubators in China and in France : a comparative analysis. International Journal of Entrepreneurship and Innovation Management, 11(3), 282-300.

McMullan, E., Chrisman, J.J. et Vesper, K. (2001). Some problems in using subjective measures of effectiveness to evaluate entrepreneurial assistance programs. Entrepreneurship Theory and Practice, 26(1), 37-54.

Merrifield, D.B. (1987). New business incubators. Journal of Business Venturing, 2(4), 277-284.

Messeghem, K., Naro, G. et. Sammut, S. (2010). Construction d'un outil stratégique d'évaluation de l'accompagnement à la création d'entreprise : apport du tableau de bord prospectif. Gestion 2000, 27(2), 95-112.

Mian, S. (1997). Assessing and managing the university technology business incubator : an integrative framework. Journal of Business Venturing, 12(4), 251-285.

Molnar, L., Adrins, D., Yolanda, B., Grimes, D., Sherman, H. et Tornatzky, L. (1997). Business incubation works. Athens, Ohio, NBIA Publications.

Oriot, F. et Misiaszek, E. (2012). Le balanced scorecard au filtre d'une PME française. Ou pourquoi les PME préfèrent le «sur-mesure ». Revue française de gestion, 6(225), 27-43. 
Pena, I. (2004). Business incubation centers and new firm growth in the Basque country. Small Business Economics, 22(3-4), 223-236.

Peters, L., Rice, M. et Sundarajan, M. (2004). The role of incubators in the entrepreneurial process. Journal of Technology Transfer, 29(1), 83-91.

Phan, P.H., Siegel, D.S. et Wright, M. (2005). Science parks and incubators : observations, synthesis and future research. Journal of Business Venturing, 20(2), 165-182.

Plosila, W. et Allen, D. (1985). Small business incubators and public policy : implications for states and local development strategies. Policy Studies Journal, 13(4), 729-734.

Ratinho, T. et Henriques, E. (2010). The role of science parks and business incubators in converging countries : evidence from Portugal. Technovation, 30(4), 278-290.

REDIs, J. (2006). Contribution à la connaissance de l'accompagnement à la levée de fonds destinée aux jeunes entreprises de croissance : le cas de la France. Revue de l'entrepreneuriat, 5(1), 73-89.

Rice, M.P. (1993). Intervention mechanisms used to influence the critical success of new ventures: an exploratory study (thèse de doctorat non publiée). Institut polytechnique Rensselaer, Troy, New York.

RiCE, M.P. (2002). Co-production of business assistance in business incubators : an exploratory study. Journal of Business Venturing, 17(2), 163-187.

Rice, M.P. et Matthews, J. (1995). Growing new ventures, creating new jobs : principles \& practices of successful business incubation. Westport, Connecticut, Quorum Books.

Rothaermel, F.T. et Thursby, M. (2005). University-incubator firm knowledge flows : assessing their impact on incubator firm performance. Research Policy, 34(3), 305-320.

SAleilles, S. (2007). Le réseautage chez les entrepreneurs néo-ruraux. Revue de l'entrepreneuriat, 6(1), 73-91.

Schwartz, M. et Gothner, M. (2009). A multidimensional evaluation of the effectiveness of business incubators : an application of the PROMETHEE Outranking Method. Environment and Planning C: Government and Policy, 27(6), 1072-1087.

Sherman, H. (1999). Assessing the intervention effectiveness of business incubation programs on new business start-ups. Journal of Developmental Entrepreneurship, 4(2), 117-133.

Sherman, H. et. Chappell, D.S. (1998). Methodological challenges in evaluating business incubators outcomes. Economic Development Quaterly, 12(4), 313-321.

Simons, R. (1995). Levers of control. Boston, Harvard Business School Press.

SMILOR, R. (1987). Managing the incubator system : critical success factors to accelerate new company development. IEEE Transactions on Engineering Management, 34(3), 146-155.

STUDDARD, N.L. (2006). The effectiveness of entrepreneurial firm's knowledge acquisition from a business incubator. The International Entrepreneurship and Management Journal 2(2), 211-225.

TAmasy, C. (2007). Rethinking technology-oriented business incubators : developing a robust policy instrument for entrepreneurship, innovation, and regional development? Growth and Change, 38(3), 460-473.

Tornatzky, L., Sherman, H. et Adkins, D. (2002). A national benchmarking analysis of technology business incubator performance and practices. Athens, Ohio, NBIA Publications. 
VALÉAU, P. (2006). L'accompagnement des entrepreneurs durant les périodes de doute. Revue de l'Entrepreneuriat, 5(1), 31-57.

Vanderstraeten, J. et Matthyssens, P. (2010). Measuring the performance of business incubators: a critical analysis of effectiveness approaches and performance measurement systems. $55^{\mathrm{e}}$ ICSB World Conference. Cincinnati, Ohio, États-Unis.

Versino, M. et Hoeser, U. (2005). The incubation of knowledge-intensive firms in Argentina : a review on the sectors' $10^{\text {th }}$ anniversary. $5^{\mathrm{e}}$ Triple Helix Conference. Turin-Milan.

Voisey, P., Gornall, L., Jones, P. et Thomas, B. (2006). The measurement of success in a business incubation project. Journal of Small Business and Enterprise Development, 13(3), 454-468. 